\title{
Effect of older age on treatment decisions and outcomes among patients with traumatic spinal cord injury
}

\author{
Henry Ahn MD PhD, Christopher S. Bailey MD, Carly S. Rivers PhD, Vanessa K. Noonan PT PhD, \\ Eve C. Tsai MD PhD, Daryl R. Fourney MD, Najmedden Attabib MD, Brian K. Kwon MD PhD, \\ Sean D. Christie MD, Michael G. Fehlings MD PhD, Joel Finkelstein MD, R. John Hurlbert MD, \\ Andrea Townson MD, Stefan Parent MD PhD, Brian Drew MD, Jason Chen MSc, Marcel F. Dvorak MD; \\ Rick Hansen Spinal Cord Injury Registry Network
}

\begin{abstract}
- Abstract
Background: Older people are at increased risk of traumatic spinal cord injury from falls. We evaluated the impact of older age ( $\geq 70 \mathrm{yr}$ ) on treatment decisions and outcomes.
\end{abstract}

Methods: We identified patients with traumatic spinal cord injury for whom consent and detailed data were available from among patients recruited (2004-2013) at any of the 31 acute care and rehabilitation hospitals participating in the Rick Hansen Spinal Cord Injury Registry. Patients were assessed by age group (< $70 \mathrm{v}$. $\geq 70 \mathrm{yr}$ ). The primary outcome was the rate of acute surgical treatment. We used bivariate and multivariate regression models to assess patient and injury-related factors associated with receiving surgical treatment and with the timing of surgery after arrival to a participating centre.

Results: Of the 1440 patients included in our study cohort, $167(11.6 \%)$ were 70 years or older at the time of injury. Older patients were more likely than younger patients to be injured by falling ( $83.1 \%$ v. $37.4 \% ; p<0.001)$, to have a cervical injury $(78.0 \%$ v. $61.6 \% ; p=$ 0.001 ), to have less severe injuries on admission (American Spinal Injury Association Impairment
Scale grade C or D: $70.5 \%$ v. $46.9 \% ; p<0.001$ ), to have a longer stay in an acute care hospital (median 35 v. $28 \mathrm{~d} ; p<0.005$ ) and to have a higher in-hospital mortality $(4.2 \%$ v. $0.6 \%$; $p<$ 0.001 ). Multivariate analysis did not show that age of 70 years or more at injury was associated with a decreased likelihood of surgical treatment (adjusted odds ratio [OR] 0.48, 95\% confidence interval [Cl] 0.22-1.07). An unplanned sensitivity analysis with different age thresholds showed that a threshold of 65 years was associated with a decreased chance of surgical treatment (OR $0.39,95 \% \mathrm{Cl} 0.19-$ 0.80 ). Older patients who underwent surgical treatment had a significantly longer wait time from admission to surgery than younger patients (37 v. $19 \mathrm{~h} ; p<0.001$ ).

Interpretation: We found chronological age to be a factor influencing treatment decisions but not at the 70-year age threshold that we had hypothesized. Older patients waited longer for surgery and had a substantially higher in-hospital mortality despite having less severe injuries than younger patients. Further research into the link between treatment delays and outcomes among older patients could inform surgical guideline development.
Competing interests: Eve Tsai has received consulting fees from BioClinica. Sean Christie has received consulting fees and a grant from Medtronic Canada. Stefan Parent has received grants from various nonprofit funding agencies and from DePuy Synthes Spine, Medtronic, K2M and EOS-Imaging; he owns shares in Spinologics. Marcel Dvorak has received research and fellowship funding, consulting fees and royalties from Medtronic; grants and travel funding from AO Spine International; and a fellowship grant from DePuy Synthes Spine.

No other competing interests were declared.

This article has been peer reviewed.

Accepted: June 10, 2015 Online: July 6, 2015

Correspondence to: Henry Ahn, ahnh@smh.ca

CMAJ 2015. DOI:10.1503/ cmaj.150085
$\mathrm{G}$ lobally there has been an epidemiologic shift in the age of patients who sustain a traumatic spinal cord injury. ${ }^{1-3}$ Although most people who have traumatic spinal cord injuries are 16-30 years old, there has been a progressive increase in the number who are over 70 . The average age at injury has increased from 29 to 40 years. ${ }^{4}$ By 2032, patients over 70 are predicted to account for most patients with new traumatic spinal cord injuries. ${ }^{5}$ This change is attributed in part to aging baby boomers. It is unknown whether the management and outcomes of these older patients differ compared with younger patients.
Older patients typically have more comorbid conditions, including cardiovascular disease, respiratory disorders, cerebrovascular disease and dementia, which are thought to increase their risk of perioperative adverse events. ${ }^{6}$ The use of anticoagulants for cardiac and cerebrovascular indications can delay timely surgical interventions. Older patients are also at increased risk of postoperative and medication-related adverse events, such as delirium. ${ }^{7}$ As a direct consequence of this perceived risk of perioperative adverse events and ambiguity about the optimal treatment for spinal cord injury in older patients, surgeons may deliberate for some time before 
making a clear therapeutic decision, they may choose nonoperative treatment ${ }^{8}$ or they may delay the surgical treatment in an effort to optimize the patient's condition medically.

Given the increasing incidence of traumatic spinal cord injury in older adults, and the potential for differences in treatment among older and younger patients, we evaluated the impact of age on treatment decisions and outcomes among patients with traumatic spinal cord injury. We hypothesized that surgical management would differ at an age threshold of 70 years.

\section{Methods}

\section{Study population}

We selected patients for our study cohort from among those recruited (2004-2013) at any of the 18 acute care and 13 rehabilitation hospitals across Canada participating in the Rick Hansen Spinal Cord Injury Registry, a prospective observational registry that collects data from people who have had a traumatic spinal cord injury. ${ }^{9}$ The registry was created to answer research questions and to facilitate the implementation of best practices. All participating sites obtained approval from their local research ethics board before enrolling patients. Any person who has reached the age of majority and who receives treatment at a participating site for a new traumatic spinal cord injury is eligible for inclusion in the registry. A core dataset is collected for all registrants, and a detailed dataset is collected for those who provide informed consent. For our study, we included only participants who provided consent and for whom a detailed registry record was available.

\section{Data collection}

We obtained the following data from the patients' registry records: age, sex, cause of injury (fall v. other), energy of trauma (high v. low), level of injury (cervical v. thoracolumbar), neurologic severity of injury and Injury Severity Score (multitrauma), Charlson Comorbidity Index,${ }^{10}$ time from injury to admission to a participating registry site and time from admission to surgery.

We grouped patients by age $(<70 \mathrm{v} . \geq 70 \mathrm{yr})$. We chose 70 years as the age threshold because it is clinically significant and affects acute clinical management. This age has been shown by others to be the "tipping point" for increased rate of death from trauma, ${ }^{11}$ specifically spinal cord injury. ${ }^{12}$ The level and neurologic severity of injury were determined at the time of injury by means of a detailed neurologic assessment, performed according to accepted international standards. ${ }^{13}$ Severity of injury was measured with the American Spinal Injury Association Impairment Scale
(AIS) (grade A = most severe, grade $\mathrm{D}=$ least severe). The Injury Severity Score is a standard trauma score that indicates the degree of trauma to major body regions. A score of 25 or more can affect care and is indicative of major trauma to another region in addition to the spine (multitrauma). ${ }^{14}$ The incidence of major complications (i.e., urinary tract infection, pneumonia, pressure ulcer and deep vein thrombosis) was obtained from hospital administrative data. Details about the Rick Hansen Spinal Cord Injury Registry dataset have been described previously. ${ }^{9}$

\section{Outcome measures}

The primary outcome measure was the rate of acute surgical treatment in the 2 age groups. The secondary outcome measure was the effect of age on the timing of surgical treatment. For this measure, we obtained data on the time from injury to admission to a participating acute care registry site and the time from admission to surgery.

\section{Statistical analysis}

We compared differences in surgery rates and timing of surgery between the 2 age groups. In addition to sex and cause of injury, our analysis accounted for neurologic severity of injury, severity of trauma and comorbid conditions as potential confounding factors that could influence decisions for treatment following traumatic spinal cord injury independent of age.

We compared categorical variables such as AIS grade and neurologic level between the 2 age groups using a $\chi^{2}$ test; continuous variables such as age at injury were compared with the nonparametric Wilcoxon rank-sum test. We performed logistic regression analysis to determine the effect of age on the likelihood of receiving acute surgical treatment; we included variables significant in the bivariate analyses based on age group as well as the Charlson Comorbidity Index because of its potential clinical significance. We performed a second multivariate analysis, using linear regression analysis, to determine the effect of age on the time from admission to surgery. Goodness of fit was checked with the Hosmer-Lemeshow test and the area under the receiver operating characteristic curve in the first model, and with the $F$ test in the second model. Standard checks for multicollinearity were also performed. We performed all analyses using SAS version 9.3 (SAS Institute Inc.).

\section{Results}

Of the 2751 participants in the registry, 1232 (44.8\%) had only core data collected because consent was not obtained for the detailed data collection (759 died or were discharged before 
consent could be obtained, 296 were approached but declined consent, and 177 had language or cognitive issues) (Figure 1). Detailed data were collected for the 1519 (55.2\%) who gave consent. Surgery data were unavailable for 79 patients, which left 1440 in our analysis cohort. Of these patients, $167(11.6 \%)$ were 70 years of age or older at the time of injury (comparable to the $10.2 \%$ of the Canadian population over the age of $70^{15}$ ). Table 1 describes the results from the bivariate (unadjusted) analyses. Older patients were significantly more likely than younger patients to have been injured by a fall $(83.1 \% \mathrm{v}$. $37.4 \% ; p<0.001)$, to be less severely injured overall (Injury Severity Score < 25: 58.2\% v. $39.1 \%$; $p=0.001)$, to have a less severe AIS grade (C or D: $70.5 \%$ v. $46.9 \% ; p<0.001)$ and to have an injury at the cervical level $(78.0 \% \mathrm{v}$. $61.6 \% ; p<0.001)$. Older patients also were significantly more likely to have major postoperative complications (i.e., urinary tract infection, pneumonia, pressure ulcer, deep vein thrombosis) $(32.5 \%$ v. $22.2 \% ; p=0.01)$. They were also significantly more likely to have a longer acute length of stay ( $35 \mathrm{v} .28 \mathrm{~d} ; p<0.005)$ and higher in-hospital mortality $(4.2 \%$ v. $0.6 \% ; p<0.001)$. Length of stay in rehabilitation hospitals did not differ significantly between the older and younger groups ( 86.5 v. $87.0 \mathrm{~d} ; p=0.8$ ).

The older patients were less likely than the younger patients to receive acute surgical treatment $(80.2 \%$ v. $87.7 \% ; p=0.008)$ (Table 1$)$. After we adjusted for neurologic severity and level, we found that older age was no longer a significant factor (adjusted odds ratio [OR] 0.48, 95\% confidence interval [CI] 0.22-1.07) (Table 2). Significant predictors of receiving acute surgical treatment were having an injury from high-energy trauma (adjusted OR 2.25, 95\% CI 1.10-4.60) and having an AIS grade A or B injury (adjusted OR 4.60, 95\% CI 2.07-10.23).

Given the near significance of age in the model for acute operative treatment, we performed a post hoc sensitivity analysis using age thresholds of 60, 65 and 75 years in addition to 70 years. Age was a significant factor in determining the odds of a patient undergoing acute surgical treatment when the threshold was 65 years (Table 3).

The comparison of the 1250 patients who received surgery is shown in Table 4. Patients aged 70 years or more experienced a significantly longer time from injury to arrival at a participating acute care hospital (median 14.5 v. 8 h; $p<0.001$ ) and a significantly longer time from admission to surgery (median 37 v. $19 \mathrm{~h} ; p<0.001$ ). In the multivariate analysis, we used a log-transformation because of the non-normality in the outcome (time from admission to surgery). Older patients still experienced a significant delay in the time from admission to surgery $(p=0.001$ ) (Appendix 1, available at www.cmaj.ca/lookup/suppl/ doi:10.1503/cmaj.150085/-/DC1). Patients with a more severe (AIS grade A or B) injury received surgery sooner after admission than those who had less severe (AIS grade C or D) injuries ( $p<$ 0.001). Neurologic level of injury was also significant $(p<0.001)$, with the shortest delay occurring among patients who had thoracolumbar injuries.

When we performed a post hoc sensitivity analysis using age thresholds of 60, 65 and 75 years in addition to 70 years, age was a significant factor associated with an increased time from admission to surgery for the thresholds of 60, 65 and 70 years, but not 75 years (Appendix 2, available at www.cmaj.ca/lookup/suppl/ doi:10.1503/cmaj.150085/-/DC1). This difference may have been due to the small cohort size of the oldest patients (age 75 and older).

\section{Interpretation}

Our study showed differences in the management of traumatic spinal cord injury between older and younger patients. We found chronological age to be a factor influencing treatment decisions, but not at the 70-year age threshold that we had hypothesized. Patients 70 years of age and older had a substantial delay in the time from injury to surgery. Their time from injury to arrival at a participating acute care centre was about twice that

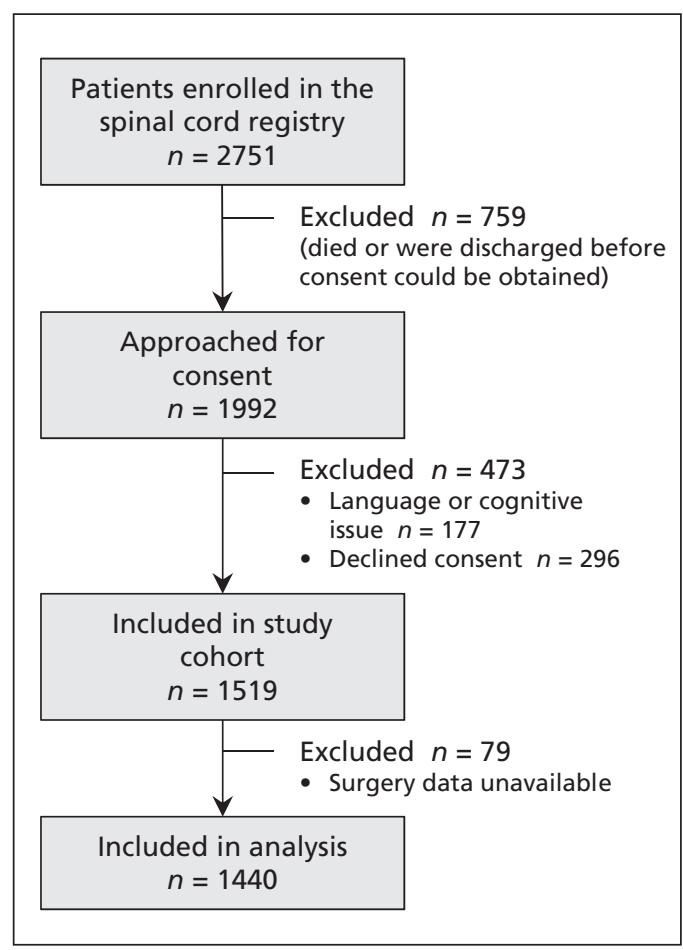

Figure 1: Selection of patients with traumatic spinal cord injury for the study cohort. 
of younger patients. Once admitted, older patients experienced a further delay to surgery, again twice that of younger patients. Mortality was significantly greater among older patients than among younger patients.

Most older patients sustained their spinal cord injuries from low-energy falls and had had less severe, neurologically incomplete (AIS grade C or D) injuries. Younger patients were more likely to experience motor complete (AIS grade A or B) injuries. Cervical injuries (78\%) resulting in incomplete injuries were most common in older people and would theoretically suggest a more favourable prognosis compared with younger patients who sustained higher energy trauma and more severe spinal cord injuries.

Table 1: Characteristics of patients with traumatic spinal cord injuries, by age group

\begin{tabular}{|c|c|c|c|}
\hline \multirow[b]{2}{*}{ Characteristic } & \multicolumn{2}{|c|}{ Age group, yr; no. (\%) of patients* } & \multirow[b]{2}{*}{$p$ valuet } \\
\hline & $\begin{array}{c}<70 y r \\
n=1273\end{array}$ & $\begin{array}{l}\geq 70 y r \\
n=167\end{array}$ & \\
\hline Sex, male & $1007(79.1)$ & $126(75.5)$ & 0.3 \\
\hline Injury from a fall & $\begin{array}{l}n=1261 \\
471(37.4)\end{array}$ & $\begin{array}{c}n=166 \\
138(83.1)\end{array}$ & $<0.001$ \\
\hline Injury from high-energy trauma & $\begin{array}{l}n=1216 \\
656(54.0)\end{array}$ & $\begin{array}{l}n=160 \\
32(20.0)\end{array}$ & $<0.001$ \\
\hline Injury Severity Score $<25$ at admission & $\begin{array}{c}n=688 \\
269(39.1)\end{array}$ & $\begin{array}{c}n=79 \\
46(58.2)\end{array}$ & 0.001 \\
\hline Charlson Comorbidity Index, median (IQR) & $0(0-0)$ & $0(0-1)$ & $<0.001$ \\
\hline Level of injury and AIS grade & $n=1036$ & $n=136$ & $<0.001$ \\
\hline C1-C4; AIS grade A, B, C & $193(18.6)$ & $27(19.9)$ & \\
\hline C5-C8; AIS grade A, B, C & $219(21.1)$ & 27 (19.9) & \\
\hline T1-S5; AIS grade A, B, C & $347(33.5)$ & $26(19.1)$ & \\
\hline All; AIS grade D & $277(26.7)$ & $56(41.2)$ & \\
\hline AIS grade & $n=1105$ & $n=142$ & $<0.001$ \\
\hline A & $467(42.3)$ & $30(21.1)$ & \\
\hline B & $120(10.9)$ & $12(8.5)$ & \\
\hline $\mathrm{C}$ & $210(19.0)$ & $41(28.9)$ & \\
\hline D & $308(27.9)$ & $59(41.6)$ & \\
\hline Neurologic level of injury & $n=1055$ & $n=141$ & 0.001 \\
\hline High cervical (C1-C4) & $308(29.2)$ & $52(36.9)$ & \\
\hline Low cervical (C5-T1) & $342(32.4)$ & $58(41.1)$ & \\
\hline Thoracic (T2-T10) & $201(19.1)$ & $20(14.2)$ & \\
\hline Thoracolumbar (T11-L2) & $204(19.3)$ & $11(7.8)$ & \\
\hline $\begin{array}{l}\text { Time from injury to RHSCIR acute care site, } \\
\text { h, median (IQR) }\end{array}$ & $8.0(3-20)$ & $14.5(6-59.5)$ & $<0.001$ \\
\hline Underwent acute surgical treatment & $1116(87.7)$ & $134(80.2)$ & 0.008 \\
\hline Had postoperative complicationsł & $\begin{array}{l}n=1008 \\
224(22.2)\end{array}$ & $\begin{array}{c}n=120 \\
39(32.5)\end{array}$ & 0.01 \\
\hline \multicolumn{4}{|l|}{ Length of stay, $d$, median (IQR) } \\
\hline Acute care hospital & $28(16-46)$ & $35(19-57)$ & $<0.005$ \\
\hline Rehabilitation hospital & $87(57-135)$ & $86.5(60-126)$ & 0.8 \\
\hline All & $112(68.5-173.5)$ & $110(66-163.0)$ & 0.8 \\
\hline In-hospital mortality & $7 \quad(0.6)$ & $7 \quad(4.2)$ & $<0.001$ \\
\hline \multicolumn{4}{|c|}{$\begin{array}{l}\text { Note: AIS grade = American Spinal Injury Association Impairment Scale grade, } \mathrm{Cl}=\text { confidence interval, IQR = interquartile } \\
\text { range, RHSCIR = Rick Hansen Spinal Cord Injury Registry. } \\
\text { *Unless stated otherwise. } \\
\text { tContinuous variables compared using Wilcoxon rank-sum test; categorical variables compared using the } \chi^{2} \text { test. } \\
\text { ‡Major complications studied were urinary tract infection, pneumonia, pressure ulcer and deep vein thrombosis. }\end{array}$} \\
\hline
\end{tabular}


Although an age threshold of 70 years did not appear to affect decisions to perform surgery in older patients, a sensitivity analysis showed a significant association between age and likelihood of surgery when the threshold was lowered to 65 years. The low number of participants in the oldest group may have resulted in a lack of power to detect the effect of age on the odds of receiving surgical treatment. Our a priori age threshold of 70 years was based on the clinical experience of the authors rather than a belief in a sharp difference in biological response at any one age. Age dichotomization in spinal cord injury and in other areas of clinical research is common, although it will be important for future work to consider both the chronological and the biological age (e.g., frailty index $)^{16}$ when determining effects on outcomes and best practice guidelines. The effect of the patient's health and factors such as surgeon preference on management and outcomes will be explored in future work.

Patients over 70 years of age experienced considerable delays between admission and surgery; similar findings were noted at age thresholds of 60 and 65 years. Various factors may have contributed to these delays. Older patients experienced a triage delay (injury to arrival at a participating acute care centre) that was twice that of younger patients. This may have been due to delays in recognizing their less severe injuries, or it may reflect a potential age-related therapeutic bias. The management delay (time from admission to surgery) was also twice as long in the older group and may have been due to a perceived lower urgency in obtaining appropriate imaging and in establishing a diagnosis and a therapeutic plan for older patients.

It may be that older patients require a more complex management plan for their comorbid conditions and that surgeons may prefer to manage incomplete cervical spinal cord injuries with a period of initial observation to assess neurologic improvement. However, even after we adjusted for injury severity, neurologic level and trauma severity, there remained a delay in time to surgery associated with patient age. Time may be required to optimize older patients' medical status, reverse anticoagulation, assess their cardiovascular risk before surgery and plan for possible prolonged postoperative ventilation. However, the older and younger patients in our cohort had similar comorbidity scores. Our analysis showed that advanced age alone was associated with delays in both triage and surgical treatment.

Despite some evidence of the benefit of early decompression, particularly in patients with incomplete neurologic injuries, ${ }^{17-19}$ uncertainty remains with respect to the potential for neurologic improvement, and this uncertainty may be amplified in older patients. Surgical delays may prolong immobilization, increase the risk of medical complications and contribute to higher mortality among older patients.

The significant differences in injury-related characteristics, timing of surgery and outcomes between older and younger patients necessitate rethinking the management of traumatic spinal cord injury among older patients. Factors relating to biological age or an objective assessment of frailty must also be considered, because clinical decisions are not made on the basis of chronological age alone. Although we have identified patients 70 years of age and older as experiencing delays in triage and delays to surgery, we do not yet have clear evidence that these delays are fundamentally responsible for increases in morbidity and mortality. Unlike older patients with a fragility hip fracture, for whom evidence-

Table 2: Factors associated with the likelihood of acute surgical treatment for traumatic spinal cord injury

\begin{tabular}{|c|c|}
\hline Factor & Adjusted OR* $(95 \% \mathrm{Cl})$ \\
\hline Intercept & NA \\
\hline Injury from high-energy (v. low-energy) trauma & $2.25(1.10-4.60)$ \\
\hline Injury Severity Score $\geq 25$ (v. < 25) & $1.28(0.61-2.72)$ \\
\hline AIS grade A or B (v. grade C or D) & $4.60(2.07-10.23)$ \\
\hline \multicolumn{2}{|l|}{ Neurologic level } \\
\hline High cervical (C1-C4) & $0.86(0.33-2.23)$ \\
\hline Low cervical (C5-T1) & $1.24(0.46-3.38)$ \\
\hline Thoracic (T2-T10) & $0.59(0.18-1.91)$ \\
\hline Thoracolumbar (T11-L2) & 1.00 (ref) \\
\hline Age at injury $\geq 70 \mathrm{yr}(\mathrm{v} .<70)$ & $0.48(0.22-1.07)$ \\
\hline Charlson Comorbidity Index & $1.07(0.72-1.59)$ \\
\hline
\end{tabular}

Table 3: Sensitivity analysis of the effect of different age thresholds on the likelihood of acute surgical treatment for traumatic spinal cord injury

\begin{tabular}{|lcccc|}
\hline $\begin{array}{l}\text { Age } \\
\text { threshold, yr }\end{array}$ & $\begin{array}{c}\text { No. of } \\
\text { patients }\end{array}$ & $\begin{array}{c}\text { Adjusted OR* } \\
(95 \% \mathrm{Cl})\end{array}$ & $\begin{array}{c}\text { Akaike } \\
\text { information } \\
\text { criterion }\end{array}$ & $\begin{array}{c}\text { Area under } \\
\text { ROC curve }\end{array}$ \\
\hline 60 & 379 & $0.54(0.27-1.08)$ & 320.4 & 0.77 \\
\hline 65 & 263 & $0.39(0.19-0.80)$ & 317.1 & 0.77 \\
\hline 70 & 167 & $0.48(0.22-1.07)$ & 320.3 & 0.77 \\
\hline 75 & 86 & $0.78(0.28-2.12)$ & 323.1 & 0.76 \\
\hline $\begin{array}{l}\text { Note: } \mathrm{Cl}=\text { confidence interval, OR = odds ratio, ROC = receiver operating characteristic. } \\
\text { *Adjusted for neurologic severity and level. }\end{array}$ \\
\hline
\end{tabular}


based therapeutic guidelines exist regarding time to treatment, ${ }^{20-23}$ further research is needed to strengthen the link between treatment delays and outcomes among older patients with spinal cord injuries.

Reducing surgical delays for traumatic spinal cord injury, regardless of age, may help maximize neurologic improvement and avoid prolonged preoperative cervical spine precautions, which often result in adverse events such as pneumonia. A policy with a mandated time frame, similar to that for the management of hip fractures, may help optimize appropriate imaging, medical clearance and urgent booking of patients with spinal cord injuries. Such an approach would circumvent any potential for surgical delay, including potential surgeon bias. An agreed upon evidence-based policy would encourage the prioritization and triage of these patients for surgical treatment when they arrive in the emergency department.

\section{Strengths and limitations}

The Rick Hansen Spinal Cord Injury Registry represents one of the largest cohorts of patients with traumatic spinal cord injury in North America, recruited from multiple acute care and rehabilitation centres across Canada. This is a major strength of our study. The size of the cohort provides sufficient power for multivariate regression analysis. Furthermore, the registry captures patients managed surgically and those nonsurgically, with a diverse spectrum of injury severity and preoperative comorbid conditions, creating a rich database for analysis that can be applied with external validity to patients in real clinical settings.

Our study has limitations. Registries contain a limited dataset. Supplemental information on reasons for surgical delay were not collected, but they should be evaluated in future studies. Consent from participants is required for enrolment in the registry to collect a comprehensive set of

Table 4: Characteristics of 1250 patients who received acute surgical treatment, by age group

\begin{tabular}{|c|c|c|c|}
\hline \multirow[b]{2}{*}{ Characteristic } & \multicolumn{2}{|c|}{ Age group, yr; no. (\%) of patients* } & \multirow[b]{2}{*}{$p$ value $\dagger$} \\
\hline & $\begin{aligned} & <70 \\
n & =1116\end{aligned}$ & $\begin{array}{c}\geq 70 \\
n=134\end{array}$ & \\
\hline \multicolumn{3}{|l|}{ Age, yr } & \multirow[t]{3}{*}{$<0.001$} \\
\hline Mean (range) & $40.8(12-69)$ & $76.0(70-92)$ & \\
\hline Median (IQR) & $41(26-54)$ & $75(72-80)$ & \\
\hline Sex, male & $872(78.1)$ & $103(76.9)$ & 0.7 \\
\hline Injury from a fall & $\begin{array}{c}n=1108 \\
406(36.6)\end{array}$ & $\begin{array}{c}n=133 \\
107(80.5)\end{array}$ & $<0.001$ \\
\hline Injury from high-energy trauma & $\begin{array}{c}n=1075 \\
609(56.7)\end{array}$ & $\begin{array}{c}n=129 \\
29(22.5)\end{array}$ & $<0.001$ \\
\hline Injury Severity Score $<25$ at admission & $\begin{array}{c}n=610 \\
219(35.9)\end{array}$ & $\begin{array}{c}n=60 \\
30(50.0)\end{array}$ & 0.03 \\
\hline Charlson Comorbidity Index, median (IQR) & $0(0-0)$ & $0(0-1)$ & $<0.001$ \\
\hline AIS grade & $n=983$ & $n=114$ & $<0.001$ \\
\hline$A$ or $B$ & $562(57.2)$ & $36(31.6)$ & \\
\hline C or D & $421(42.8)$ & $78(68.4)$ & \\
\hline Neurologic level of injury & $n=933$ & $n=111$ & 0.004 \\
\hline High cervical (C1-C4) & $254(27.2)$ & $38(34.2)$ & \\
\hline Low cervical (C5-T1) & $300(32.2)$ & $47(42.3)$ & \\
\hline Thoracic (T2-T10) & $192(20.6)$ & $16(14.4)$ & \\
\hline Thoracolumbar (T11-L2) & $187(20.0)$ & $10(9.0)$ & \\
\hline $\begin{array}{l}\text { Time from injury to RHSCIR acute care site, } h \text {, } \\
\text { median (IQR) }\end{array}$ & $8(3-19)$ & $15(6-56)$ & $<0.001$ \\
\hline $\begin{array}{l}\text { Time from admission to surgery, } h \text {, } \\
\text { median (IQR) }\end{array}$ & $19(10-41)$ & $37(15.5-82)$ & $<0.001$ \\
\hline \multicolumn{4}{|c|}{$\begin{array}{l}\text { Note: AIS grade = American Spinal Injury Association Impairment Scale grade, IQR = interquartile range, RHSCIR = Rick Hansen } \\
\text { Spinal Cord Injury Registry. } \\
\text { *Unless stated otherwise. } \\
\text { tContinuous variables compared using Wilcoxon rank-sum test; categorical variables compared using the } \chi^{2} \text { test. }\end{array}$} \\
\hline
\end{tabular}


injury-related and follow-up data useful for exploring the complex and heterogeneous nature of traumatic spinal cord injury. Standardization of the internationally recommended neurologic assessment and more widespread data collection in Canadian hospitals would greatly improve participant numbers, as would changing the registry to an opt-out model (whereby patients would be included in the registry automatically unless they refused to be registered). ${ }^{24}$

The rationale for surgical delay in older patients can only be inferred. Further work is needed to assess the extent to which immobilization and surgical delay might lead to increased rates of adverse events such as pneumonia, blood clots, pulmonary embolism and aspiration. The rate of adverse events among the older patients in our study was higher than the rate among younger patients. This difference may be influenced by comorbid conditions and other variables. ${ }^{7}$

\section{Conclusion}

Patients with traumatic spinal cord injury who were aged 70 years or older had less severe incomplete neurologic injuries, most often at the cervical level and resulting from low-energy falls, than younger patients. Older patients also experienced delays in transfer to a specialized treatment centre and further delays from admission to surgery. They incurred significantly higher rates of adverse events and had higher mortality. The causal link between treatment delays and outcomes requires further investigation before we can recommend adoption of system-wide policies similar to those adopted for fragility fractures of the hip.

\section{References}

1. Knútsdóttir S, Thórisdóttir H, Sigvaldason K, et al. Epidemiology of traumatic spinal cord injuries in Iceland from 1975 to 2009. Spinal Cord 2012;50:123-6.

2. Oliver M, Inaba K, Tang A, et al. The changing epidemiology of spinal trauma: a 13-year review from a level I trauma centre. Injury 2012;43:1296-300.

3. Pirouzmand F. Epidemiological trends of spine and spinal cord injuries in the largest Canadian adult trauma center from 1986 to 2006. J Neurosurg Spine 2010;12:131-40.

4. Jackson AB, Dijkers M, Devivo MJ, et al. A demographic profile of new traumatic spinal cord injuries: change and stability over 30 years. Arch Phys Med Rehabil 2004;85:1740-8.

5. Lewis R, Noonan V, Zhong G, et al. What will traumatic spinal cord injury care look like in 20 years in Canada? Resource planning by forecasting. Can J Surg 2013;56(Suppl 2):S65-6.

6. Krassioukov AV, Furlan JC, Fehlings MG. Medical comorbidities, secondary complications, and mortality in elderly with acute spinal cord injury. J Neurotrauma 2003;20:391-9.

7. Street JT, Noonan VK, Cheung A, et al. Incidence of acute care adverse events and long-term health-related quality of life in patients with TSCI. Spine J 2015;15:923-32.

8. Roth EJ, Lovell L, Heinemann AW, et al. The older adult with a spinal cord injury. Paraplegia 1992;30:520-6.

9. Noonan VK, Kwon BK, Soril L, et al. RHSCIR Network. The Rick Hansen Spinal Cord Injury Registry (RHSCIR): a national patient-registry. Spinal Cord 2012;50:22-7.

10. Charlson ME, Pompei P, Ales KL, et al. A new method of classifying prognostic comorbidity in longitudinal studies: development and validation. J Chronic Dis 1987;40:373-83.
11. Caterino JM, Valasek T, Werman HA. Identification of an age cutoff for increased mortality in patients with elderly trauma. Am J Emerg Med 2010;28:151-8.

12. Fassett DR, Harrop JS, Maltenfort M, et al. Mortality rates in geriatric patients with spinal cord injuries. J Neurosurg Spine 2007;7:277-81

13. Waring WP III, Biering-Sorensen F, Burns S, et al. 2009 review and revisions of the international standards for the neurological classification of spinal cord injury. J Spinal Cord Med 2010;33: 346-52.

14. Baker SP, O'Neill B, Haddon W Jr, et al. The injury severity score: a method for describing patients with multiple injuries and evaluating emergency care. J Trauma 1974;14:187-96.

15. 2011 census of Canada: topic-based tabulations. Ottawa: Statistics Canada; 2013. Available: www12.statcan.gc.ca/census-recensement /2011/dp-pd/tbt-tt/Rp-eng.cfm?LANG=E\&APATH=3\&DETAIL $=0 \& \mathrm{DIM}=0 \& \mathrm{FL}=\mathrm{A} \& \mathrm{FREE}=0 \& \mathrm{GC}=0 \& \mathrm{GID}=0 \& \mathrm{GK}=0 \& \mathrm{GRP}=1$ $\& \mathrm{PID}=102009 \& \mathrm{PRID}=0 \& \mathrm{PTYPE}=101955 \& \mathrm{~S}=0 \&$ SHOWALL $=$ $0 \&$ SUB $=0 \&$ Temporal $=2011 \&$ THEME $=88 \& \mathrm{VID}=0 \&$ VNAMEE $=\& \mathrm{VNAMEF}=($ accessed 2015 June 17) .

16. Mitnitski AB, Mogilner AJ, Rockwood K. Accumulation of deficits as a proxy measure of aging. ScientificWorldJournal 2001;1:323-36.

17. Dvorak MF, Noonan VK, Fallah N, et al. The influence of time from injury to surgery on motor recovery and length of hospital stay in acute traumatic spinal cord injury: an observational Canadian cohort study. J Neurotrauma 2015:32:645-54.

18. Fehlings MG, Vaccaro A, Wilson JR, et al. Early versus delayed decompression for traumatic cervical spinal cord injury: results of the Surgical Timing in Acute Spinal Cord Injury Study (STASCIS). PLoS ONE 2012; 7:e32037.

19. van Middendorp JJ, Hosman AJ, Doi SA. The effects of the timing of spinal surgery after traumatic spinal cord injury: a systematic review and meta-analysis. J Neurotrauma 2013;30:1781-94.

20. Health indicators. Toronto: Canadian Institute for Health Information; 2012. Available: https://secure.cihi.ca/free_products/ health_indicators_2012_en.pdf (accessed 2015 June 17).

21. Improving time to surgery: emergency room, preoperative and immediate postoperative clinical practice guidelines for the management of hip fracture patients. Bone and Joint Health Network; 2010. Available: http://boneandjointcanada.com/wp -content/uploads/2014/05/ER-Pre-op-Clinical-Practice-Guidelines -20101101_Final.pdf (accessed 2015 June 17).

22. Minimum standards for the management of hip fracture in the older person. Chatswood (Australia): New South Wales Agency for Clinical Innovation; 2014. Available: www.aci.health.nsw.gov. au/ data/assets/pdf file/0004/222727/Minimum-Standards-for -the-Management-of-Hip-Fractures.pdf (accessed 2015 June 17).

23. Quality standard for hip fracture [NICE quality standard 16]. London (UK): National Institute for Health and Care Excellence; 2012. Available: guidance.nice.org.uk/qs16 (accessed 2015 June 17).

24. Tu JV, Willison DJ, Silver FL, et al.; Investigators in the Registry of the Canadian Stroke Network. Impracticability of informed consent in the Registry of the Canadian Stroke Network. N Engl J Med 2004;350:1414-21.

Affiliations: St. Michael's Hospital, University of Toronto Spine Program (Ahn), Toronto, Ont.; Western University (Bailey), London, Ont.; Rick Hansen Institute (Rivers, Noonan, Chen), Vancouver, BC; University of British Columbia (Noonan, Kwon, Townson, Dvorak), Vancouver, BC; The Ottawa Hospital, Ottawa Hospital Research Institute, University of Ottawa (Tsai), Ottawa, Ont.; University of Saskatchewan (Fourney), Saskatoon, Sask.; Horizon Health Network/Dalhousie University (Attabib), St. John, NB; Dalhousie University (Christie), Halifax, NS; Division of Neurosurgery and Spinal Program, University of Toronto (Fehlings), Toronto, Ont.; Sunnybrook Health Sciences Centre, University of Toronto (Finkelstein), Toronto, Ont.; University of Calgary Spine Program (Hurlbert), Calgary, Alta.; Hôpital du Sacré-Coeur de Montréal, Hôpital SteJustine, Université de Montréal (Parent), Montréal, Que.; Hamilton General Hospital, McMaster University (Drew), Hamilton, Ont.

Contributors: Henry Ahn, Christopher Bailey, Marcel Dvorak, Vanessa Noonan and Carly Rivers collaborated on the study design, the manuscript plan and project management, and oversaw data analysis and the drafting and review of the manuscript. Jason Chen led the data analysis, collabo- 
rated with the other authors on the interpretation of data, and provided critical review of the manuscript, including drafting the statistical methods of the manuscript. All of the other authors participated in the set-up of the Rick Hansen Spinal Cord Injury Registry and the study, recruited participants into the registry, participated in drafting the manuscript and provided critical feedback on the manuscript. Vanessa Noonan and Marcel Dvorak led the inception and set-up of the study registry. All of the authors approved the final version of the manuscript to be published and agreed to be guarantors of the work.

Funding: This study and the Rick Hansen Spinal Cord Injury Registry are supported by funding from Health Canada, Western Economic Diversification Canada, and the Governments of Alberta, British Columbia, Manitoba and Ontario. The funders had no role in the study or reporting of the study. The Rick Hansen Institute sponsored the Rick Hansen Spinal Cord Injury Registry and this study.
Acknowledgement: The authors thank the Rick Hansen Spinal Cord Injury Registry Network and all of the participating sites: G.F. Strong Rehabilitation Centre, Vancouver General Hospital, Foothills Medical Centre, Glenrose Rehabilitation Hospital, Royal Alexandra Hospital, University of Alberta Hospital, Royal University Hospital, Saskatoon City Hospital, Winnipeg Health Sciences Centre, Toronto Western Hospital, Toronto Rehabilitation Institute, St. Michael's Hospital, Sunnybrook Health Sciences Centre, Hamilton General Hospital, Hamilton Health Sciences - Regional Rehabilitation Centre, Victoria Hospital, University Hospital, Parkwood Institute, The Ottawa Hospital Rehabilitation Centre, The Ottawa Hospital - Civic Campus, Hôpital de l'Enfant Jésus, Institut de réadaptation en déficience physique de Québec, Centré de réadaptation Lucie-Bruneau, Institut de réadaptation Gingras-Lindsay-de-Montréal, Hôpital du Sacré-Cour de Montréal, Nova Scotia Rehabilitation Centre, QEII Health Sciences Centre, Saint John Regional Hospital, Stan Cassidy Centre for Rehabilitation, St. John's Health Sciences Centre and Dr. Leonard A. Miller Rehabilitation Centre.

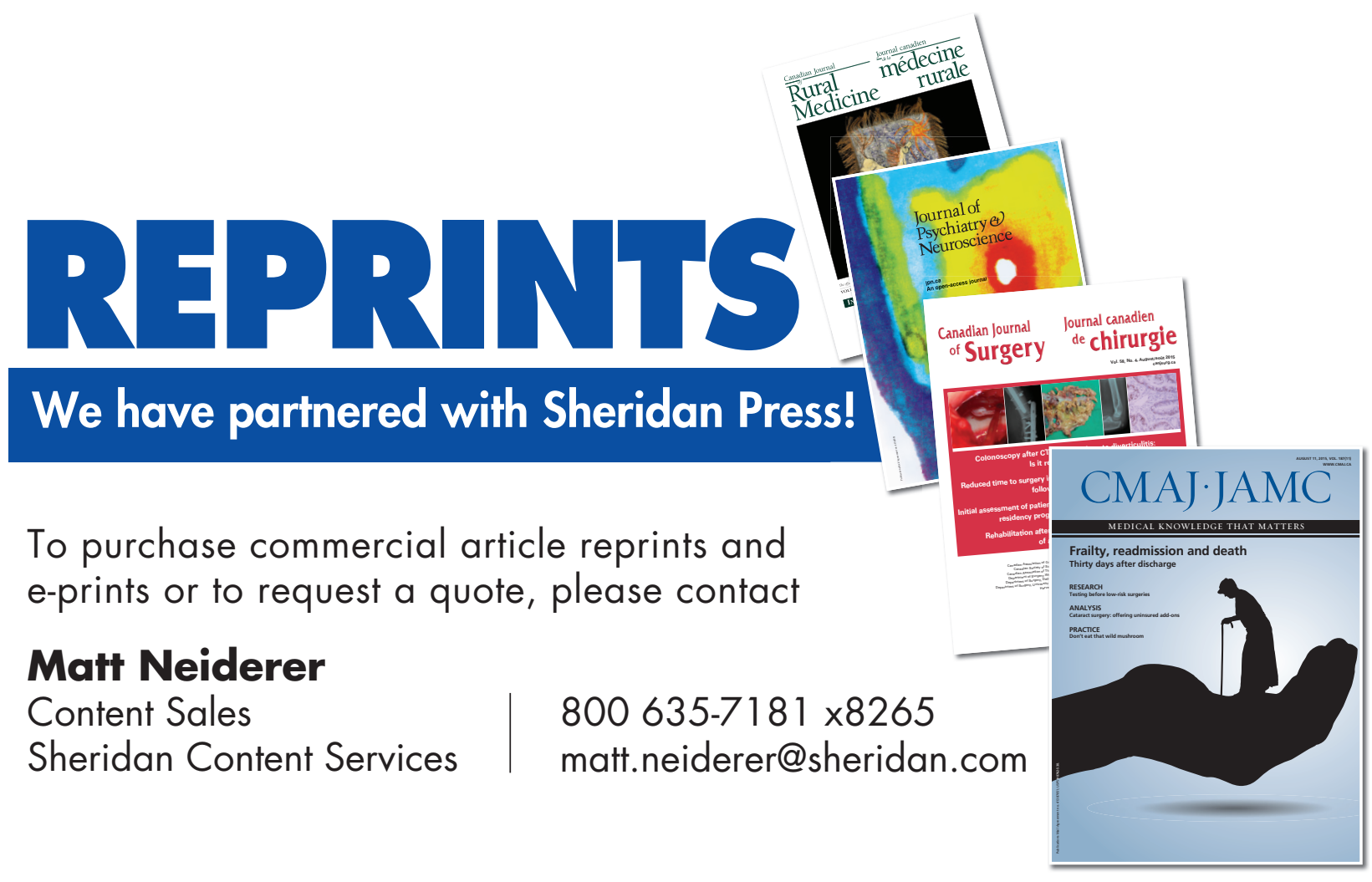

